\title{
Simulation of Electric Field Distribution in Water Treed XLPE HV Underground Cable Using COMSOL Multiphysics
}

\author{
Terapong Boonraksa $\mathrm{a}^{\mathrm{a}}$, Narupon Promvichai ${ }^{\mathrm{b}}$, Tassanai Supanarapan ${ }^{\mathrm{b}}$, \\ Kelvin Melckzedeck Minja ${ }^{\mathrm{b}}$, Pius Victor Chombo $^{\mathrm{b}}$ and Boonruang Marungsri ${ }^{\mathrm{b}}$ \\ ${ }^{a}$ School of Electrical Engineering, Faculty of Engineering, Rajamangala University of Technology \\ Rattanakosin, 96 Mu 3 Thanon Phutthamonthon Sai 5, Salaya, Phutthamonthon, Nakhon Pathom, 73170, Thailand. \\ ${ }^{\mathrm{b}}$ School of Electrical Engineering, Suranaree University of Technology, 111 University Avenue, \\ Suranaree SubDistric, Muang Distric, Nakhon Ratchasima, 30000, Thailand. \\ *Corresponding Author: Tel. 08-3334-5771, E-mail address: terapong.boo@rmutr.ac.th
}

\begin{abstract}
This paper studies the electric field distribution of water treed Cross-linked polyethylene (XLPE) insulation of HV underground cable under $\mathrm{NaCl}$ solution assigned in water treeing. It is significant to study electric field distribution in order to examine the harmful propagation in presence of $\mathrm{NaCl}$ solution. COMSOL Multiphysics was used in modeling and simulating insulation layers of XLPE cable, vented and bow-tie water treeing, and $\mathrm{NaCl}$ solution. The propagation was studied in vented and bow-tie water treeing under $\mathrm{NaCl}$ solution when $\mathrm{AC}$ peak voltage was applied to the copper conductor. The results showed that the maximum field strength exists at the tip of water needle for Vented water treeing and on the sides toward electric field strength for Bow-tie water treeing. This maximum value may lead the formation of conducting channel toward electric field strength. The presence of $\mathrm{NaCl}$ solution has seen to greatly influence the formation of conducting channels than DI water when assigned in the vented type water treeing.
\end{abstract}

Keywords: Water treeing, Electric fields distribution, XLPE underground cable, COMSOL Multiphysics.

\section{Introduction}

Water treeing is the pre-breakdown process in the presence of moisture which causes degradation in the polymeric material due to partial discharge and progressing through parts under electric stress in extremely non-uniform fields. Cross-linked polyethylene (XLPE) is used as insulating material in high voltage underground cable for distribution systems due to excellent mechanical, physical, chemical and electrical properties. XLPE cables are sometimes used in the humid environment for a long-time service under electric stress which can lead to degradation in the form of "water treeing"(1). Water treeing was first detected in 1969 by Miyashita. Water treeing occurs chiefly as a result of deterioration during application of a voltage while the cables are immersed in the ionic solution. It originated from porous regions in the polyethylene and ionic solution has important effects on water treeing ${ }^{(2)}$. Water treeing growth occurs in polyethylene cable insulations. It has been found that the vented water trees are more dangerous than bow-tie trees as a result of the difference in growth behavior. Vented trees are diffuse structures, growing in many kinds of polymers ${ }^{(3)}$. Water treeing regions contain a wide range of chemical species, with various forms of carbonyl and metal ions and water being dominant. Water treeing takes place in the direction of the electric field and in a polar amorphous region of the polymer ${ }^{(4)}$. In copper sulfate solutions having an influence on water treeing growth in XLPE insulation cables when compared with other solutions. Electrical conductivity properties and molecular size of ionic solutions have an influence on water treeing growth ${ }^{(5)}$. Water trees growth in XLPE cables is increased under the action of temperature cycling of the ionic solution. The cations play an important dominant role in the initiation and growth of water trees. The polymer chains play a role in the decomposition of the polymer under the action of an applied electric field ${ }^{(6,7)}$. Mechanical properties, moisture, expansion 
of micropores, and adjacent micropores connection caused by capillary expansion are the main reasons for the acceleration of water treeing at high temperatures ${ }^{(8)}$.

This paper has studied the effects of the electric field in water treed XLPE of the high voltage underground cable under $\mathrm{NaCl}$ solution. The growth of water treeing is greatly caused by the presence of ionic solutions especially $\mathrm{NaCl}$ solution in an underground environment which lead hydrophilic track in small cracks and/or weak points inside of XLPE insulation. Both Vented and Bow-tie water treeing were simulated by COMSOL Multiphysics software. The first part of this paper describes the simulation procedures. The second part shows the propagation of electric field strength in XLPE insulation underground cable.

\section{Methods}

\subsection{XLPE Underground Cable}

A single core $22 \mathrm{kV}$ XLPE insulated underground cable was used as a specimen in this study. The cross-section of XLPE cable is shown in Fig. 1. More information has been given $\mathrm{in}^{(9)}$. This underground cable is mostly used in distribution systems in Thailand.

Useful layers used in the study are a copper conductor with a radius of $4.165 \mathrm{~mm}$, inner semiconductor $4.95 \mathrm{~mm}$, XLPE insulation $10.45 \mathrm{~mm}$, and outer semiconductor 11.25 $\mathrm{mm}$. All radii were measured from the center of the copper conductor.
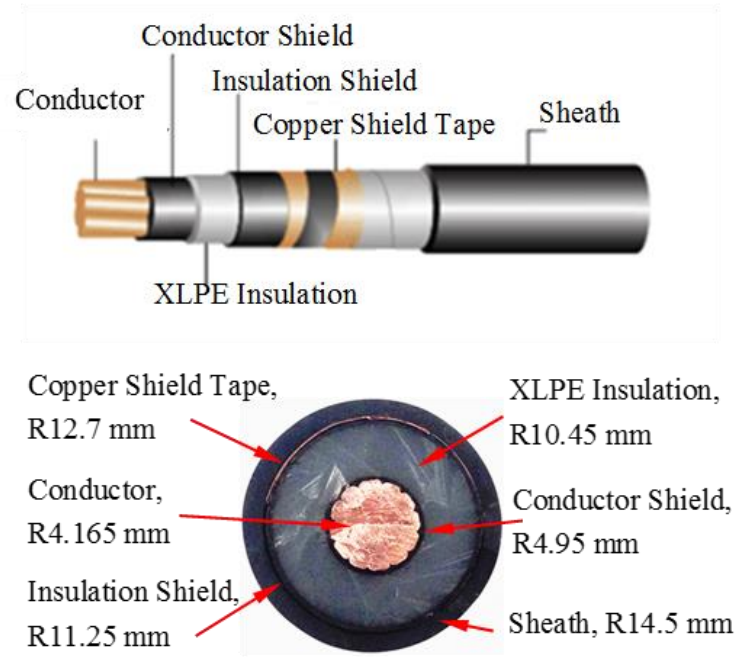

Fig. 1. Cross-section of $22 \mathrm{kV}$ XLPE Underground Cable.

\section{$2.2 \quad$ Ionic solution}

$\mathrm{NaCl}$ solution was used for the study of the electric field. The relative permittivity and bulk conductivity of the ionic solution $(\mathrm{NaCl})$, semiconductors, the Cross-linked polyethylene (XLPE), and copper are shown in Table 1.

Table 1: The parameters of tested materials

\begin{tabular}{|c|c|c|}
\hline Parameter & $\begin{array}{c}\text { Relative } \\
\text { Permittivity }\end{array}$ & $\begin{array}{c}\text { Bulk Conductivity } \\
(\mathrm{S} / \mathrm{m})\end{array}$ \\
\hline $\mathrm{NaCl}$ & 30.23 & 1.049 \\
\hline DI Water & 81.00 & 0.0002 \\
\hline Semiconductor & 100.00 & $2 \times 10^{-3}$ \\
\hline XLPE & 2.30 & $1 \times 10^{-17}$ \\
\hline Copper & 1.00 & $5.8 \times 10^{7}$ \\
\hline
\end{tabular}

\subsection{Modeling of Water treeing}

A. Vented water treeing

The model was created between the outer semiconductor and XLPE layers. It was drilled down $1.5 \mathrm{~mm}$ to acts as a water needle as shown in Fig. 2. and assigned $\mathrm{NaCl}$ solution.

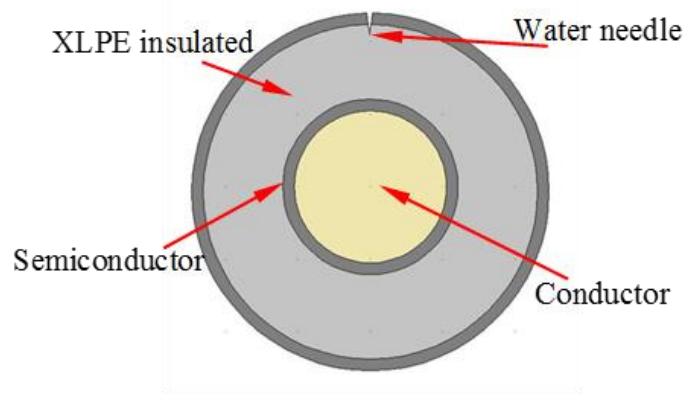

Fig. 2. Modeling of Vented water treeing.

\section{B. Bow-tie water treeing.}

The model of Bow-tie water treeing was created by micro-voids inside the XLPE insulation. Three types of microvoids with elliptical shapes were created and set parallel with electric field from the conductor. Their minor radii were $0.2 \mathrm{~mm}$. The micro-voids were assigned with DI water. 


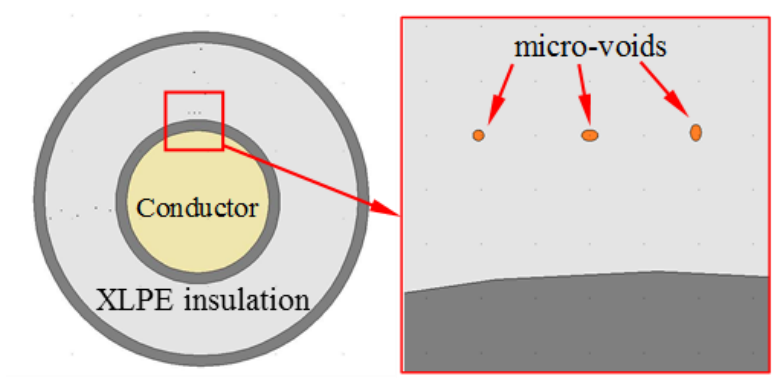

Fig. 3. Modeling of Bow-tie water treeing.

\subsection{Simulation Procedure}

Vented type Water treeing of radius $1.5 \mathrm{~mm}$ was initiated across outer semiconducting layer and XLPE layer with $\mathrm{NaCl}$ solution assigned in it. Bow-tie water treeing with minor radii of $0.2 \mathrm{~mm}$ were initiated parallel with electric field from the copper conductor. Unchanged $2 \mathrm{Uo}=24 \mathrm{kV} 50$ $\mathrm{Hz}$, AC power supply (where Uo is rated line to neutral voltage of the cable) was applied to the copper conductor. The effects of electric fields in Vented type water treeing with $\mathrm{NaCl}$ solution and Bow-tie water treeing with DI water were investigated in COMSOL Multiphysics.

\section{Results}

\subsection{Electric Field Strength in Vented Water Treeing}

Figure 4 shows Electric field distribution in simulated Vented water treeing with $\mathrm{NaCl}$ solution assigned in water treeing. Fig. 5 shows the observed Vented water treeing from the experiment ${ }^{(5)}$.

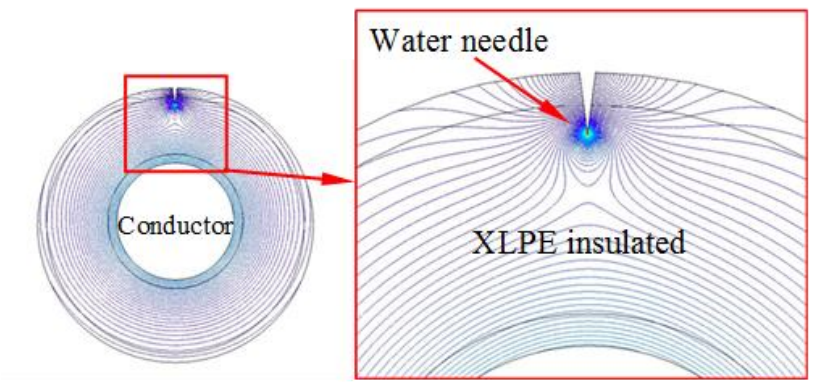

Fig. 4. Electric field Distribution in vented water treeing.

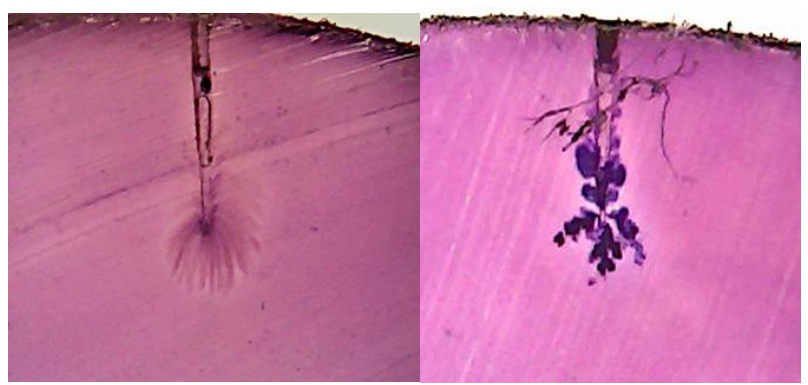

Fig. 5. Observed Vented water treeing referred from Ref. 5.

From Fig. 4, simulation result shows that the electric field strength at the tip of water needle is maximum than the other parts. The maximum electric field strength was 4.88 $\mathrm{kV} / \mathrm{mm}$ with $\mathrm{NaCl}$ solution and $3.49 \mathrm{kV} / \mathrm{mm}$ with DI water solution. This means that conducting channels may initiate at the tip of water needle and then propagate faster toward electric field strength in the presence of $\mathrm{NaCl}$ solution than in DI water solution. Since Vented water treeing may initiate in low electric field strength ${ }^{(10)}$, it may initiate and grow easily compared to other types of water treeing. Also, the initiation and growth of conducting channels from the tip of water needle towards electric field strength were observed in an experimented specimen in Boonraksa, 2014 as shown in Fig. 5.

\subsection{Electric Field Strength in Bow-tie Water Treeing}

Figure 6 shows simulated Bow-tie water treeing with DI water assigned in water treeing. Fig.7 shows the observed Bow-tie water treeing from the experimented specimen in Boonraksa, 2014.

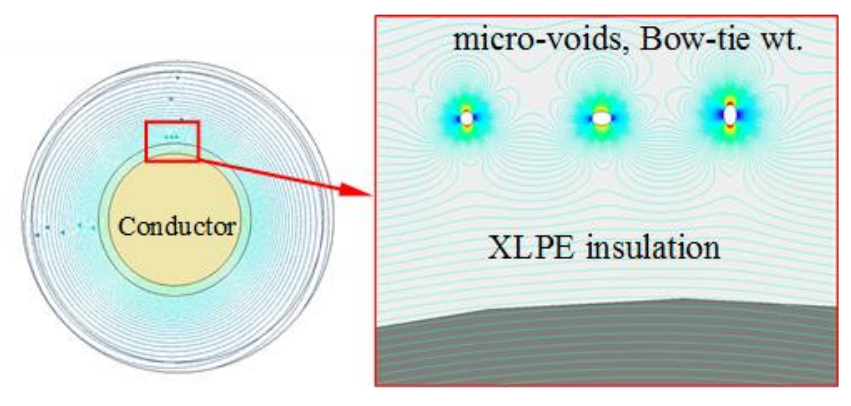

Fig. 6. Electric field Distribution in Bow-tie water treeing. 


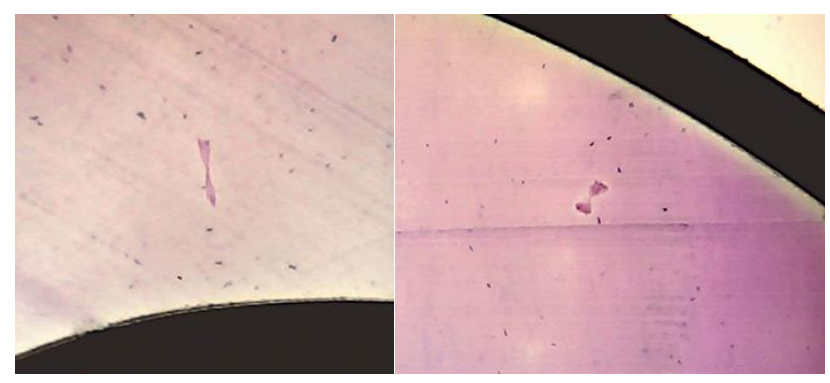

Fig. 7. Observed Bow-tie water treeing referred from Ref. 5.

From Fig. 6, the maximum values of electric field strengths were observed on the sides of electric fields. The maximum value of $0.089 \mathrm{kV} / \mathrm{mm}$ close to the micro-voids in direction of electric field was observed. At this value of electric field strength, the conducting channels may be initiated and grow toward the direction of electric field strength. Fig. 7 shows the growth of conducting channels on the micro-void towards electric field strength ${ }^{(5)}$.

\section{Conclusions}

The electric field strength in water treed XLPE insulation under the effects of $\mathrm{NaCl}$ with vented type water treeing of $1.5 \mathrm{~mm}$ radius and Bow-tie water treeing with minor axis of $0.2 \mathrm{~mm}$ were studied in COMSOL Multiphysics. In the presence of $\mathrm{NaCl}$ solution occupied in external defects of the XLPE cable, Conducting Channels may be initiated and grow faster than in DI water solution. It has been seen that the maximum electric field occurs at the tip of water needle (Vented water treeing) and side of microvoid (Bow-tie water treeing) toward electric field. This causes the formation of conducting channels on the sides of maximum electric strength.

\section{Acknowledgment}

This research was supported by Rajamangala University of Technology Rattanakosin, Thailand. The authors wish to gratefully acknowledge their financial support. The authors wish to gratefully acknowledge Laboratory of High Voltage Insulation Technologies in Suranaree University of Technology, Thailand.

\section{References}

(1) Boonraksa, T. and Marungsri, B. : "Role of Ionic Solutions Affect Water Treeing Propagation in XLPE Insulation for High Voltage Cable", World Academy of
Science, Engineering and Technology, 2014.

(2) Miyashita, T. : "Deterioration of Water-Immersed Polyethylene Coated Wire by Treeing", Proceedings 1969, IEEE-NEMA Electrical Insulation Conference, Boston(USA), 1969.

(3) Steennis, E. F. and Kreuger, F. H. : "Water Treeing in Polyethylene Cables", IEEE Transactions on Electrical Insulation, Vol. 25, No. 5, pp. 989-1028, 1990.

(4) $\mathrm{Xu}$ J. J. and Boggs, S. A. : "The Chemical Nature of Water Treeing", Theories and Evidence, IEEE Electrical Insulation Magazine, Vol. 10, No.5, pp. 29 - 37, 1994.

(5) Boonraksa, T. and Marungsri, B. : "Characteristics of Water Treeing in XLPE High Voltage Underground Cable for $22 \mathrm{kV}$ Distribution System in Thailand" The 17th Asian Conference on Electrical Discharge (ACED 2014), Bangkok, Thailand, 2014.

(6) Qureshi, M.I., Malik, N.H. and Al-Arainy, A.A. : "Impact of cations toward the water tree propensity in crosslinked polyethylene insulation", Journal of King Saud University - Engineering Sciences, Vol. 23, No. 1, pp. 43-48, 2010.

(7) Al-Arainy, A. A., Ahaideb, A. A., Qureshi M I. and Malik, N.H. : "Statistical Evaluation of Water Tree Lengths in XLPE Cables at Different Temperatures", IEEE Transactions on Dielectrics and Electrical Insulation, Vol. 11, No. 6, pp. 995-1006, 2004.

(8) Wang, Z., Marcolongo, P., Lemberg, J. and Wright, P.K. : "Mechanical Fatigue as a Mechanism of Water Tree Propagation in TR-XLPE" IEEE Transactions on Dielectrics and Electrical Insulation Vol. 19, No. 1, 2012.

(9) Thai Yazaki, Online document, Retrieved from http://www.nre.co.th/2014/downloads -spec-tiscatalog/category/13-thaiyazaki.html, 2014.

(10) El-Zein, A., El Bahy, M.M., and Talaat, M. : “Types of Electrical Trees in Solid Insulation under electrical and Mechanical Energy Basis", Twelve International middle east power system conference, MEPCOM 2008, pp.8084, 2008. 